\title{
New bioinformatic tools for analysis of nucleotide modifications in eukaryotic rRNA
}

\author{
DOROTA PIEKNA-PRZYBYLSKA, ${ }^{1}$ WAYNE A. DECATUR, ${ }^{1}$ and MAURILLE J. FOURNIER \\ Department of Biochemistry and Molecular Biology, University of Massachusetts, Amherst, Massachusetts 01003, USA
}

\begin{abstract}
This report presents a valuable new bioinformatics package for research on rRNA nucleotide modifications in the ribosome, especially those created by small nucleolar RNA:protein complexes (snoRNPs). The interactive service, which is not available elsewhere, enables a user to visualize the positions of pseudouridines, 2'-O-methylations, and base methylations in threedimensional space in the ribosome and also in linear and secondary structure formats of ribosomal RNA. Our tools provide additional perspective on where the modifications occur relative to functional regions within the rRNA and relative to other nearby modifications. This package of new tools is presented as a major enhancement of an existing but significantly upgraded yeast snoRNA database available publicly at http://people.biochem.umass.edu/sfournier/fournierlab/snornadb/. The other key features of the enhanced database include details of the base pairing of snoRNAs with target RNAs, genomic organization of the yeast snoRNA genes, and information on corresponding snoRNAs and modifications in other model organisms.
\end{abstract}

Keywords: rRNA; modification; ribosome; box C/D snoRNA; box H/ACA snoRNA; yeast

\section{INTRODUCTION}

Small nucleolar RNAs (snoRNAs) are stable RNAs within ribonucleoprotein complexes called snoRNPs (snorps) localized in the nucleoli of eukaryotes. Based on structural elements within the snoRNAs and the associated core proteins, snoRNAs are grouped into one of three classes. One class has only one member, the MRP RNA, while the other two classes are composed of large families of RNAs. A few of the snoRNP complexes, including the MRP species, are involved in key cleavages that occur during processing of ribosomal RNA (rRNA); however, the vast majority create modified nucleotides in ribosomal RNA and spliceosomal RNA. The snoRNAs in one large family possess short sequence elements termed boxes "C" and " $D$ " and most of these snoRNAs guide 2'-O-methylation (Nm) to specific nucleotides in target RNAs. The snoRNAs in the other large family possess elements called boxes " $\mathrm{H}$ " and "ACA" and most of these snoRNAs guide conversion of uridine to pseudouridine $(\Psi)$ at specific sites in the

\footnotetext{
${ }^{1}$ These authors contributed equally to this work.

Reprint requests to: Maurille J. Fournier, Department of Biochemistry and Molecular Biology, Lederle Graduate Research Tower, University of Massachusetts, Amherst, MA 01003, USA; e-mail: 4nier@biochem.umass. edu; fax: (413) 545-3291.

Article published online ahead of print. Article and publication date are at http://www.rnajournal.org/cgi/doi/10.1261/rna.373107.
}

substrate RNA (for review, see Bertrand and Fournier 2004; Kiss 2004; Meier 2005; Yu et al. 2005). In both the rRNA cleaving and modifying processes the snoRNP complex interacts directly with the RNA substrate through complementary sequences in the snoRNA. Catalysis in the case of the modifying snoRNPs is mediated by an associated core protein: in Saccharomyces cerevisiae, Nop1p, the fibrillarin ortholog, carries out the addition of a methyl group to the 2' hydroxyl moiety of the ribose, and Cbf5p, the dyskerin ortholog, catalyzes the isomerization of uridine to pseudouridine.

The ribosomes in Escherichia coli contain only a few pseudouridines and 2'-O-methylations; however, in eukaryotes the total number of modified nucleotides ranges from about 100 in yeast to close to 200 in humans (Maden 1990; Bakin and Ofengand 1995; Ofengand and Bakin 1997; Ofengand and Fournier 1998; Rozenski et al. 1999; Lestrade and Weber 2006). Interestingly, phylogenetic comparison reveals that the locations of two-thirds of the rRNA modifications are conserved between yeast and humans (Ofengand 2002). Little is known about the roles of the modifications in rRNA, but visualization of the sites in the three-dimensional (3D) space of the ribosome shows that most occur in tight constellations, particularly in the large subunit. These regions include conserved, functionally important portions of the ribosome involved in tRNA binding, peptide bond formation, extrusion of the nascent 
chain through the polypeptide tunnel, and bridging of the two subunits (Decatur and Fournier 2002; Ofengand 2002).

$S$. cerevisiae is presently the best eukaryotic model organism for analyzing the rRNA modifications guided by snoRNAs. In addition to being especially well suited for genetic manipulations, it appears that essentially all of the $\Psi$ and Nm rRNA modification sites are known and that all of the corresponding guide snoRNAs have also been identified (Lowe and Eddy 1999; Schattner et al. 2004; Torchet et al. 2005; W.A. Decatur and M.J. Fournier, unpubl.). In conjunction with the Yeast Genome Database and the snoRNA literature, it is possible to genetically deplete cells of one or more specific guide snoRNAs in a relatively straightforward manner and thereby create strains lacking the corresponding modifications.

The availability of high-resolution structures of the ribosome is clearly a major advance in structural biology (Ban et al. 2000; Klein et al. 2001; Ogle et al. 2001; Yusupov et al. 2001; Yusupova et al. 2001; Berisio et al. 2003; Schuwirth et al. 2005; Selmer et al. 2006). In the present context, this information has led to the development of the first 3D modification maps for the ribosome (e.g., http:// people.biochem.umass.edu/sfournier/fournierlab/snornadb/; Decatur and Fournier 2002; Hansen et al. 2002; Ofengand 2002; Badis et al. 2003; Omer et al. 2003; Kirpekar et al. 2005; Mengel-Jorgensen et al. 2006). Such maps allow researchers to correlate modifications with specific aspects of ribosome structure and function and thereby allow better informed experimentation about effects of modifications. With these genetic and computational tools it is possible to create yeast strains depleted of one or several modifications in rRNA domains of interest, and then assess effects on different aspects of ribosome synthesis and function. In addition to depleting snoRNAs to block specific modifications, modifications can also be disrupted by mutating snoRNAs, most effectively in the guide elements that target the snoRNP to the rRNA (e.g., King et al. 2003).

Here, we present a valuable new bioinformatics capability for research on rRNA nucleotide modifications in the ribosome. This service is not available elsewhere and enables users to view the positions of the modified nucleotides in yeast cytoplasmic rRNA, in both the secondary structure of the rRNA and, importantly, in the three-dimensional context of the ribosome. These capabilities provide important perspectives on where the modifications occur relative to functional regions within the target RNA and relative to other nearby modifications. The package of tools for visualizing modified nucleotides in the secondary structure of the RNA and 3D space of the ribosome is included in a significantly upgraded database of S. cerevisiae snoRNAs (Samarsky and Fournier 1999), publicly available at http://people.biochem.umass.edu/ sfournier/fournierlab/snornadb/.

As part of the upgrade of the database, we present the pairings between the target RNAs and the guide elements for all snoRNAs that direct modification (as well as those known for the processing snoRNAs). In addition to reporting the basic properties of the $S$. cerevisiae snoRNAs, the upgraded database also provides information about corresponding snoRNAs and modifications in other model organisms. These latter features together with the relevant two-dimensional (2D) modification map of rRNA will facilitate studies on phylogenetic conservation of snoRNAs and modifications. Taken together, the present collection of tools and information in the database should provide an important boost to investigations on the mechanisms of guided RNA nucleotide modifications and the long-standing questions about effects of modifications on ribosome structure and function. In the following sections we briefly summarize the updates made to the existing $S$. cerevisiae snoRNA database and then describe in more detail the new package of tools for visualizing the positions of modified nucleotides in the yeast ribosome.

\section{RESULTS}

\section{Upgrading of the yeast snoRNA database}

Our yeast snoRNA database is the only comprehensive collection of information about the full complement of the S. cerevisiae snoRNAs and modifications they guide. Several internet resources refer to this database, including the snoRNA-LBME database of Human snoRNAs (Lestrade and Weber 2006), the Plant snoRNA database (Brown et al. 2003), and the S. cerevisiae Genome Database (Dwight et al. 2004). Substantial progress has been made in recent years in identifying the full set of yeast snoRNAs and assigning functions to the various species. This information is now fully integrated into the database. Presently, 76 snoRNA species have been identified, and essentially all of the 100 known $\mathrm{Nm}$ and $\Psi$ modifications in yeast rRNA have been assigned to a specific guide snoRNA-with experimental validation-or to proteins, in two cases (Lowe and Eddy 1999; Lapeyre and Purushothaman 2004; Schattner et al. 2004; Torchet et al. 2005; W.A. Decatur and M.J. Fournier, unpubl.).

The updated database includes all known C/D box and H/ACA box snoRNAs for S. cerevisiae. Many of the new listings reflect outstanding progress made by different computational and experimental approaches and combinations of these approaches (Olivas et al. 1997; Lowe and Eddy 1999; Edvardsson et al. 2003; McCutcheon and Eddy 2003; Schattner et al. 2004; Ghazal et al. 2005; Torchet et al. 2005; Davis and Ares 2006; Houalla et al. 2006). The catalog of snoRNAs in $S$. cerevisiae is very well developed and may be close to completion. In addition to accounting for all $\mathrm{Nm}$ and $\Psi$ modifications in rRNA, recent search strategies have yielded few novel snoRNAs. Any new snoRNAs will presumably be specific for other substrate RNAs that also colocalize with the snoRNPs. 
The major portion of the snoRNA database is arranged into two sections provided on the menu bar as "Find snoRNA" and "Target RNA" (Fig. 1). The links facilitate accessing information by different parameters, such as "name," "type of snoRNA," "target RNA," or "nucleotide targeted" (Fig. 1). Ribosomal RNAs are not the only RNAs in yeast targeted for modification by guide snoRNAs. One exception exists at present, the U2 snRNA, which contains a $\Psi$ guided to a conserved position by snR81 (Ma et al. 2005); snR81 also guides a $\Psi$ in $25 \mathrm{~S}$ rRNA. In the database, the modified nucleotides are indicated in the target RNA sequences and linked to a page with details about the assigned snoRNA. Since several C/D- and H/ACA-box snoRNAs have guidelike domains that are not complementary to

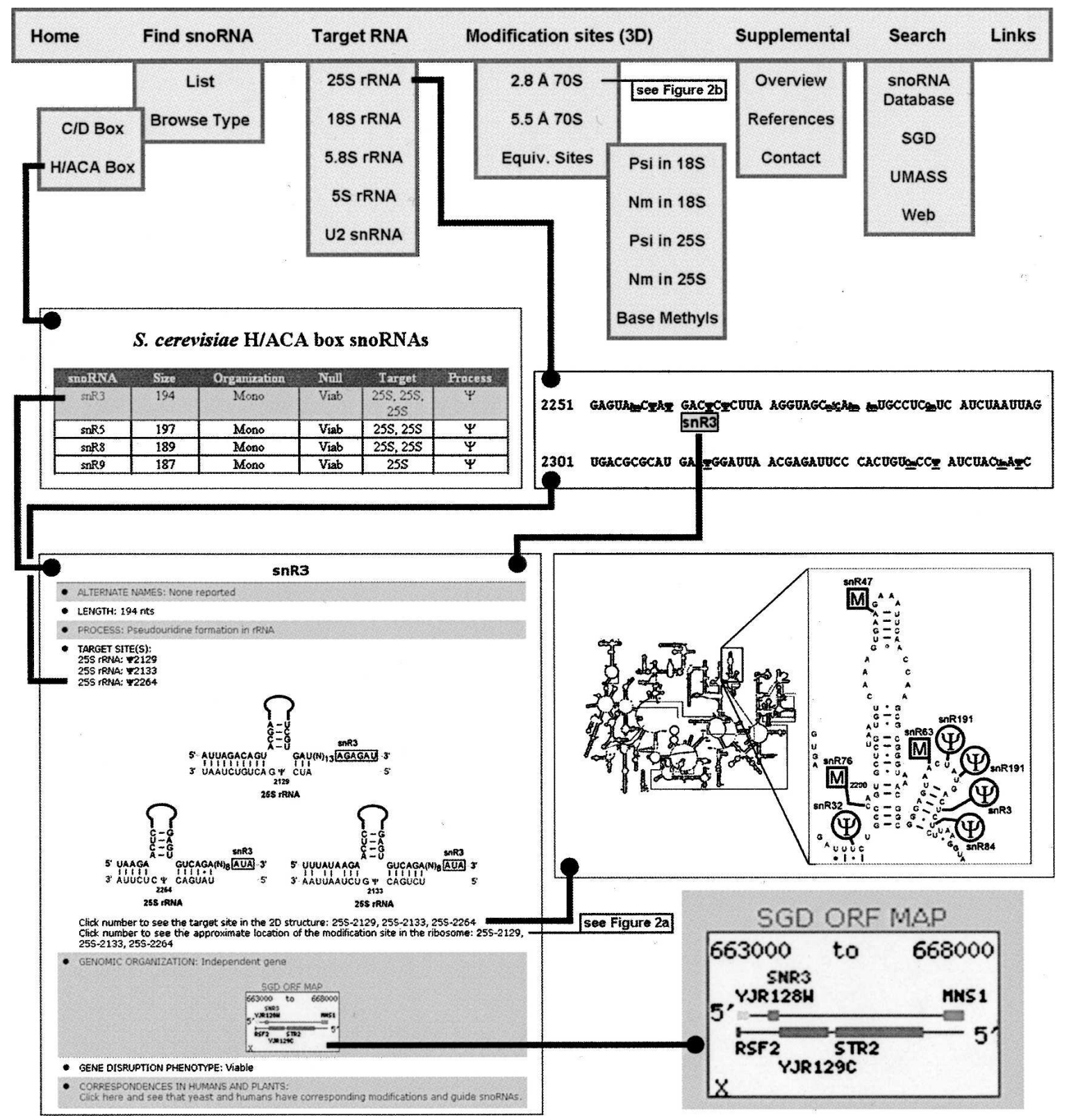

FIGURE 1. Properties of the yeast snoRNA database. The menu bar (top) shows the sections of the database, and portions of the associated links are illustrated in exploded views. "Find snoRNA" and "Target RNA" facilitate searching by different parameters, such as: "name," "type of snoRNA," "target RNA," or "nucleotide targeted." A representative portion of the main page for an individual snoRNA is shown (below the main menu). Each such page provides basic information about "the snoRNA," "the DNA coding unit," "base pairing with the target RNA," and "corresponding snoRNAs in other organisms." The positions of the modified nucleotides in rRNA can be visualized in "linear," "secondary structure," and "3D structure" formats, with nearby modified nucleotides viewable in linear and secondary structure formats (middle right). Several links are provided to external sites such as Plant and Human snoRNA databases and the Saccharomyces cerevisiae Genome Database (SGD), as exemplified by the SGD ORF map link shown (lower right). 
ribosomal RNAs, the possibility remains that other target RNAs will be identified for these known snoRNAs. Furthermore, the updated database illustrates that a few typical snoRNAs with two guide motifs can target three and even four nonadjacent modifications in RNA. Previously, some C/D guide snoRNAs had been shown to guide three modifications; however, in those cases two of the modifications were immediately adjacent. In 2004, Schattner and colleagues showed that H/ACA guide snoRNAs could target as many as four natural $\Psi$ modifications with a single snoRNA (Schattner et al. 2004). The upgraded database includes this new information and will inform investigators involved in predicting guide functions that while snoRNAs are not indiscriminately "promiscuous," some are quite "polygamous."

Separate pages provided for each individual snoRNA include details such as "sequence," "function," "genomic organization," "literature citation(s)," and figure(s) illustrating the base-pairing potential of the snoRNA with the verified target RNA(s). Additionally we provide information about corresponding snoRNAs and modifications in other model organisms. Links are also provided to other relevant databases including the $S$. cerevisiae Genome Database (Dwight et al. 2004), the yeast methylation guide snoRNA database of the Lowe laboratory (Lowe and Eddy 1999), the snoRNA-LBME database of human snoRNAs (Lestrade and Weber 2006), the Plant snoRNA database (Brown et al. 2003), the MODOMICS database of RNA modification pathways (Dunin-Horkawicz et al. 2006), and PubMed.

In the upgraded version of the yeast snoRNA database the numbering system for modified nucleotides in rRNA was standardized and now corresponds to the coding sequence for each rRNA at the $S$. cerevisiae Genome Database (www.yeastgenome.org; Dwight et al. 2004). Because this resource is the central repository of genomic data for $S$. cerevisiae, our alignment with the genomic rDNA sequences remedies a long-standing problem within the yeast rRNA modification field, namely, that no standard numbering system existed for identifying specific nucleotides even within highly conserved regions. We also provide tables of both the old and new equivalents that can be found under the "Modification sites (3D)" tab in the database to aid colleagues using the previous systems of nomenclature.

The individual snoRNA Web pages contain appropriate links to additional pages showing the positions of modifications in target RNAs, presented in linear, secondary structure, and three-dimensional structure formats. The 2D and 3D models provide additional perspectives on where the modifications occur relative to functional regions within the target RNA and to other nearby modifications, as described below.

\section{Tools for visualizing the locations of modified nucleotides in the $3 \mathrm{D}$ ribosome}

With our new tools, modifications can now be readily visualized in the secondary structure of rRNA and in the full ribosome in three dimensions. The availability of atomic resolution structures of full prokaryotic ribosomes and individual subunits now makes it possible to examine particular regions and functional elements in close detail (Ban et al. 2000; Klein et al. 2001; Ogle et al. 2001; Yusupov et al. 2001; Yusupova et al. 2001; Berisio et al. 2003; Schuwirth et al. 2005; Selmer et al. 2006). Such information does not yet exist for the yeast ribosome; thus we adopted the prokaryotic model to create this tool and have deduced the locations of the modification sites. Importantly, it is clear that the $3 \mathrm{D}$ structure of the ribosome is very highly conserved, which follows from the remarkable conservation of the secondary structure of rRNA in nature, including archaea, protists, yeast, plants, humans, and other animals (Cannone et al. 2002). For example, the structures of the large ribosomal subunits have been solved for organisms in two of the three domains of life-for the eubacteria Thermus thermophilus, Escherichia coli, and Deinococcus radiodurans and the archaeon Haloarcula marismortui. The overall tertiary organization is highly similar despite differences in the rRNA sequences. In fact, significant portions of the prokaryotic structures fit into models of the yeast ribosome as determined by cryoelectron microscopy, including the common rRNA core, 15 of the 40 S proteins, and 28 of the 60S proteins (Spahn et al. 2001, 2004). However, because models of the $80 \mathrm{~S}$ ribosome are too incomplete at present, the yeast models available provide no advantages over the structures used here and, in fact, are unwieldy to use for nonspecialists.

The yeast modifications were mapped onto the model of the complete $70 \mathrm{~S}$ crystal structure of $T$. thermophilus at 5.5- $\AA$ resolution, which contains tRNAs at the A, P, and $\mathrm{E}$ sites, and a fragment of mRNA (Yusupov et al. 2001). On the main page for each individual snoRNA, links are provided that allow each yeast-equivalent modification site to be visualized in the $3 \mathrm{D}$ space of the ribosome. The tool for visualizing the modifications in $3 \mathrm{D}$ space also gives the user the ability to highlight or "paint" the location of multiple modified nucleotides in the ribosome (Fig. 2). The browser window that displays the ribosome contains a panel on the left with a series of toggle buttons corresponding to the nucleotides modified in yeast. Thus, modified nucleotides of interest in disparate parts of the rRNA sequence can be selected and highlighted. This ability is significant because it enables the user to envision where modified nucleotides are located relative to each other and relative to the functional regions in the $3 \mathrm{D}$ context of the ribosome. While the benefits of the 3D perspective are obvious, we underscore this with one example. The 3D modification maps have shown for the first time that several modified nucleotides in different secondary structure domains of the large subunit can be visualized on intersubunit surfaces in the full ribosome, where the subunits join and form bridges. This tool is not 
A

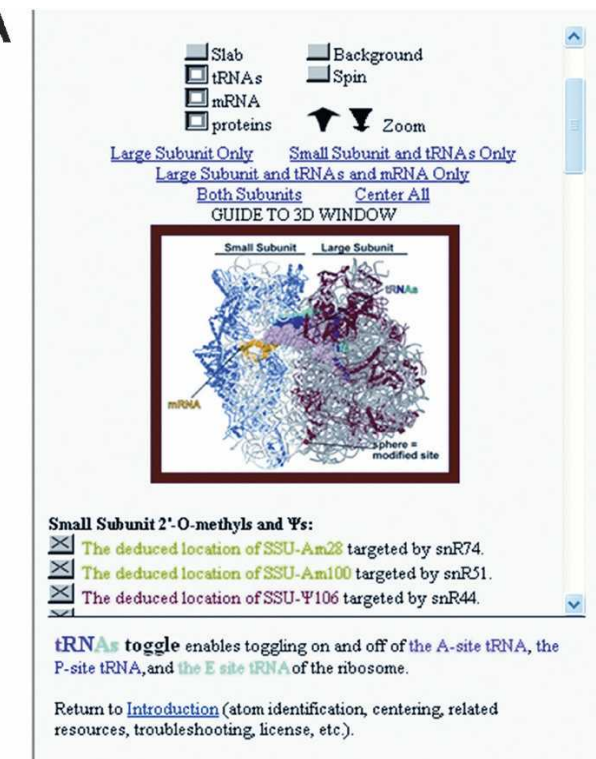

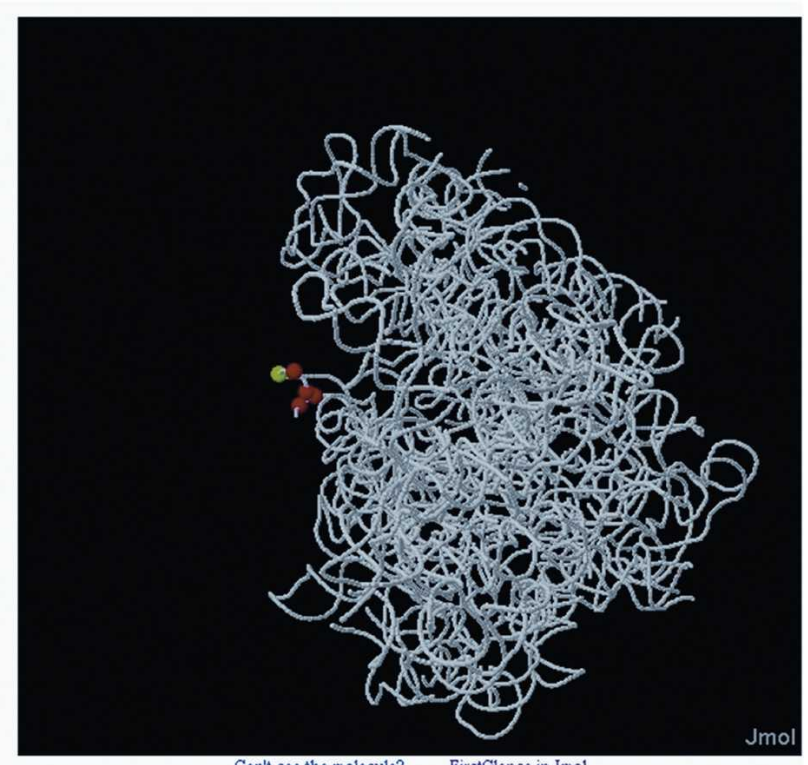

Can't see the molecule? Firstclance in Jmol fter resizing this window, use the browser's ReloadRefresh to force Inol to resize accordingly. Pleas wait until vou see the molecule before reloading/refreshing. Whr?

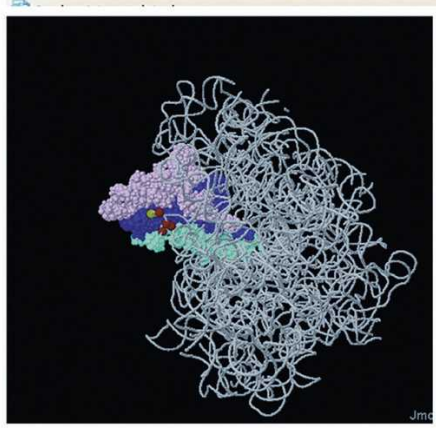

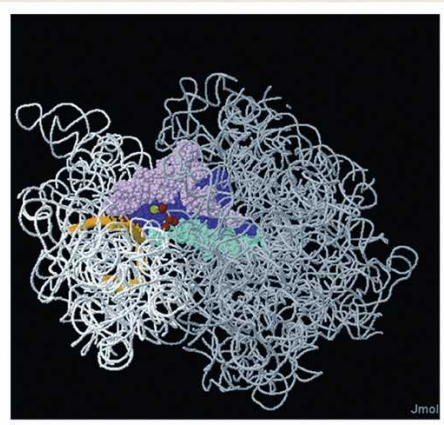

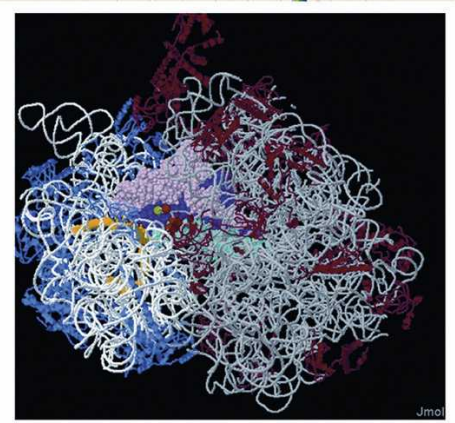

B
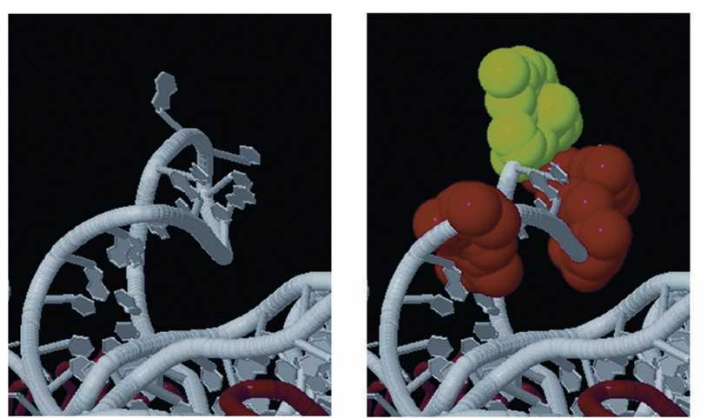

FIGURE 2. Three-dimensional visualization of the sites of rRNA modification in the ribosome. The region featured is the multifunctional intersubunit bridge formed by helix 69, which contains a cluster of five modifications created by snoRNPs. ( $A$ ) Helix 69 depicted in different perspectives of the large subunit and complete ribosome. A panel at the left contains buttons for selecting "pseudouridines" (red), " 2 '-Omethylations" (green), and "base methylations" (orange). The molecular view on the right includes the large subunit in the 5.5- $\AA$ structure with nucleotides equivalent to those modified in yeast helix 69 highlighted; proteins, tRNAs, mRNA, and the small subunit are hidden. The smaller offsets in panel $A$ present the same perspective as in the main view window, but with components made visible sequentially using the convenience control buttons: tRNAs (bottom left), rRNA of the small subunit and mRNA (bottom middle), and proteins of the small and large subunit (bottom right). (B) Helix 69 in a higher resolution structure $(2.8 \AA)$; using the " $2.8 \AA 70 S^{\prime}$ ” tool. The panels show the absence (left) and presence (right) of highlighted nucleotides equivalent to those modified in yeast.

limited to the yeast modifications created by snoRNPs, but also includes modifications made by proteins, such as base methylations.
A block of "convenience buttons" provides an interface for easily controlling the interactive views of the ribosome model. In addition to typical manipulations, such as 
controlling the degree of zoom or whether the molecule rotates, specialized controls manage the visibility of different molecular components, such as the tRNAs or an individual subunit (Fig. 2). The ability to hide the ribosomal proteins facilitates visualizing selected nucleotides immersed deeply in the structure. In the same vein, the "slab" toggle limits visibility to a thin central slab parallel to the screen, producing a clearer view of the centered moiety in the perspective selected.

With another tool available under the section "Modification sites (3D)" (Fig. 1), the user is able to perform similar visualizations using a model of the prokaryotic ribosome solved to atomic resolution $(2.8 \AA$ ) (Selmer et al. 2006). This model provides a greater degree of structural detail; however, whereas the two tRNAs at the P and E sites are clearly observed, only a fragment of the anticodon stem-loop of the tRNA bound at the A site is visible, due to disorder. Tables listing the modified nucleotides of yeast cytoplasmic rRNA with equivalent nucleotides in prokaryote rRNA are also provided in this section. The interactive $3 \mathrm{D}$ visualization strategy uses the Jmol applet (http:// jmol.sourceforge.net/; Herráez 2006), which obviates the need for additional software downloads in a modern, Javaenabled browser.

\section{DISCUSSION}

The significantly upgraded snoRNA database and package of new tools complement one another and support studies in the snoRNA and modification fields. Since the population of snoRNAs and guided modifications in $S$. cerevisiae are the best characterized for any organism, this database is a valuable asset for researchers working with snoRNAs and modifications in other organisms as well. Our database also includes information and links that are useful for phylogenetic studies on conservation of snoRNAs and modifications. Since different organisms have diverse RNA sequences, the secondary structure modification maps we provide will assist users in determining if a particular modification in another organism corresponds to one in yeast.

The tools for visualizing the position of modified nucleotides in the $3 \mathrm{D}$ ribosome should be of great help in considering effects that modifications have on ribosome functions. The $2.8-\AA$ and $5.5-\AA 3 \mathrm{D}$ modification maps show where a particular modification occurs relative to functional centers, neighboring RNA structures, and nearby proteins. Moreover, although the modifications are distributed throughout the rRNA sequences, our tools enable the viewer to see how these nucleotides are clustered in several regions of the ribosome. An early example of how this capability can benefit research was shown in a study from our laboratory on effects of depleting pseudouridines concentrated in the yeast peptidyl transferase center of the large subunit. The positions of six modifications under study were viewed within the crystal structure of the large subunit of the archaeon $H$. marismortui, and changes in the A-loop structure were inferred as the basis of a $20 \%$ decrease in the translation rate stemming from loss of a particular pseudouridine (King et al. 2003). In addition to addressing issues of modification effects, the new tools will be valuable in studies of how snoRNP function interfaces with rRNA and ribosome synthesis. In the context of human health, defects in snoRNP components have been linked thus far to three human diseases: cartilage-hair hypoplasia, dyskeratosis congenita, and Prader-Willi syndrome (Ridanpaa et al. 2001; Fatica and Tollervey 2003; Ruggero et al. 2003; Mochizuki et al. 2004; Gonzales et al. 2005; Meier 2005; Kishore and Stamm 2006; Yoon et al. 2006).

\section{MATERIALS AND METHODS}

A first step in construction of the database was standardization of the numbering system for modified nucleotides in yeast rRNA and preparation of RNA secondary structure maps showing the precise sites of modification. The source of information for the rRNA sequences was the $S$. cerevisiae Genome Database (www.yeast genome.org; Dwight et al. 2004). The secondary structure modification maps were prepared using data available on the "Comparative RNA Web Site" (www.rna.icmb.utexas.edu/; Cannone et al. 2002). Sequences of all the guide elements are now given in a graphical format that clearly illustrates the complementarity with the substrate RNA. The illustrations rely in most cases on published data with the appropriate references listed on the main page for each snoRNA, with additional secondary structure and sequence elements of the snoRNAs modeled with supporting information gathered using Mfold (www.bioinfo. rpi.edu/applications/mfold/rna/form1.cgi; Mathews et al. 1999; Zuker 2003). E. coli equivalents of the nucleotides modified in yeast were deduced from alignment of sequences (GenBank entry J01695) and comparison of secondary structure maps using data from the European ribosomal RNA database (www.psb.ugent.be/ rRNA/) and "Comparative RNA Web Site" (www.rna.icmb. utexas.edu/; Cannone et al. 2002). Stylistic elements and arrangement of the interface for the updated yeast snoRNA database were fashioned after the very effective format used for the human database, snoRNABase, at the Laboratoire de Biologie Moléculaire Eucaryote (LBME) in Toulouse, France (Lestrade and Weber 2006).

For the 3D molecular display, the Jmol (jmol.sourceforge.net/) JAVA applet is used, with the interface adapted from "FirstGlance in Jmol” (www.bioinformatics.org/firstglance/; Herráez 2006). PDB entries for the $70 \mathrm{~S}$ ribosome of $T$. thermophilus (1GIX, 1GIY, 2j00, 2j01; Yusupov et al. 2001; Yusupova et al. 2001; Selmer et al. 2006) are available at the Protein Databank (www.pdb.org). The rRNA in the ribosome is displayed as a backbone trace and nucleotides corresponding to those modified in yeast are shown as "space-filled" spheres with this code: 2'-O-methylation in green, pseudouridylation in red, and base methylation in orange.

\section{ACKNOWLEDGMENTS}

This work is supported by a grant to M.J.F. from the U.S. Public Health Service (GM19351). We thank Venki Ramakrishnan for 
sharing coordinate information for the 2.8 - $\AA 70$ S ribosome of T. thermophilus prior to publication.

Received November 3, 2006; accepted December 4, 2006.

\section{REFERENCES}

Badis, G., Fromont-Racine, M., and Jacquier, A. 2003. A snoRNA that guides the two most conserved pseudouridine modifications within rRNA confers a growth advantage in yeast. RNA 9: 771779.

Bakin, A. and Ofengand, J. 1995. Mapping of the 13 pseudouridine residues in Saccharomyces cerevisiae small subunit ribosomal RNA to nucleotide resolution. Nucleic Acids Res. 23: 3290-3294.

Ban, N., Nissen, P., Hansen, J., Moore, P.B., and Steitz, T.A. 2000. The complete atomic structure of the large ribosomal subunit at $2.4 \AA$ resolution. Science 289: 905-920.

Berisio, R., Schluenzen, F., Harms, J., Bashan, A., Auerbach, T., Baram, D., and Yonath, A. 2003. Structural insight into the role of the ribosomal tunnel in cellular regulation. Nat. Struct. Biol. 10: 366-370.

Bertrand, E. and Fournier, M.J. 2004. The snoRNPs and related machines: Ancient devices that mediate maturation of rRNA and other RNAs. In The nucleolus (ed. M.O.J. Olson), pp. 223-257. Kluwer Academic/Plenum Publishers, New York.

Brown, J.W., Echeverria, M., Qu, L.H., Lowe, T.M., Bachellerie, J.P., Huttenhofer, A., Kastenmayer, J.P., Green, P.J., Shaw, P., and Marshall, D.F. 2003. Plant snoRNA database. Nucleic Acids Res. 31: 432-435.

Cannone, J.J., Subramanian, S., Schnare, M.N., Collett, J.R., D'Souza, L.M., Du, Y., Feng, B., Lin, N., Madabusi, L.V., Muller, K.M., et al. 2002. The comparative RNA web (CRW) site: An online database of comparative sequence and structure information for ribosomal, intron, and other RNAs. BMC Bioinformatics 3: 2 .

Davis, C.A. and Ares Jr., M. 2006. Accumulation of unstable promoter-associated transcripts upon loss of the nuclear exosome subunit Rrp6p in Saccharomyces cerevisiae. Proc. Natl. Acad. Sci. 103: 3262-3267.

Decatur, W.A. and Fournier, M.J. 2002. rRNA modifications and ribosome function. Trends Biochem. Sci. 27: 344-351.

Dunin-Horkawicz, S., Czerwoniec, A., Gajda, M.J., Feder, M., Grosjean, H., and Bujnicki, J.M. 2006. MODOMICS: A database of RNA modification pathways. Nucleic Acids Res. 34: D145-D149.

Dwight, S.S., Balakrishnan, R., Christie, K.R., Costanzo, M.C., Dolinski, K., Engel, S.R., Feierbach, B., Fisk, D.G., Hirschman, J., Hong, E.L., et al. 2004. Saccharomyces genome database: Underlying principles and organisation. Brief. Bioinform. 5: 9-22.

Edvardsson, S., Gardner, P.P., Poole, A.M., Hendy, M.D., Penny, D., and Moulton, V. 2003. A search for H/ACA snoRNAs in yeast using MFE secondary structure prediction. Bioinformatics 19: 865873.

Fatica, A. and Tollervey, D. 2003. Insights into the structure and function of a guide RNP. Nat. Struct. Biol. 10: 237-239.

Ghazal, G., Ge, D., Gervais-Bird, J., Gagnon, J., and Abou Elela, S. 2005. Genome-wide prediction and analysis of yeast RNase III-dependent snoRNA processing signals. Mol. Cell. Biol. 25: 2981-2994.

Gonzales, B., Henning, D., So, R.B., Dixon, J., Dixon, M.J., and Valdez, B.C. 2005. The Treacher Collins syndrome (TCOF1) gene product is involved in pre-rRNA methylation. Hum. Mol. Genet. 14: 2035-2043.

Hansen, M.A., Kirpekar, F., Ritterbusch, W., and Vester, B. 2002. Posttranscriptional modifications in the A-loop of $23 \mathrm{~S}$ rRNAs from selected archaea and eubacteria. RNA 8: 202-213.
Herráez, A. 2006. Biomolecules in the computer. Jmol to the rescue. Biochem. Mol. Biol. Educ. 34: 255-261.

Houalla, R., Devaux, F., Fatica, A., Kufel, J., Barrass, D., Torchet, C., and Tollervey, D. 2006. Microarray detection of novel nuclear RNA substrates for the exosome. Yeast 23: 439-454.

King, T.H., Liu, B., McCully, R.R., and Fournier, M.J. 2003. Ribosome structure and activity are altered in cells lacking snoRNPs that form pseudouridines in the peptidyl transferase center. Mol. Cell 11: 425-435.

Kirpekar, F., Hansen, L.H., Rasmussen, A., Poehlsgaard, J., and Vester, B. 2005. The archaeon Haloarcula marismortui has few modifications in the central parts of its $23 \mathrm{~S}$ ribosomal RNA. J. Mol. Biol. 348: 563-573.

Kishore, S. and Stamm, S. 2006. The snoRNA HBII-52 regulates alternative splicing of the serotonin receptor 2C. Science 311: 230232.

Kiss, T. 2004. Biogenesis of small nuclear RNPs. J. Cell Sci. 117: 59495951.

Klein, D.J., Schmeing, T.M., Moore, P.B., and Steitz, T.A. 2001. The kink-turn: A new RNA secondary structure motif. EMBO J. 20: 4214-4221.

Lapeyre, B. and Purushothaman, S.K. 2004. Spb1p-directed formation of Gm2922 in the ribosome catalytic center occurs at a late processing stage. Mol. Cell 16: 663-669.

Lestrade, L. and Weber, M.J. 2006. snoRNA-LBME-db, a comprehensive database of human H/ACA and C/D box snoRNAs. Nucleic Acids Res. 34: D158-D162.

Lowe, T.M. and Eddy, S.R. 1999. A computational screen for methylation guide snoRNAs in yeast. Science 283: 1168-1171.

Ma, X., Yang, C., Alexandrov, A., Grayhack, E.J., Behm-Ansmant, I., and Yu, Y.T. 2005. Pseudouridylation of yeast U2 snRNA is catalyzed by either an RNA-guided or RNA-independent mechanism. EMBO J. 24: 2403-2413.

Maden, B.E. 1990. The numerous modified nucleotides in eukaryotic ribosomal RNA. Prog. Nucleic Acid Res. Mol. Biol. 39: 241-303.

Mathews, D.H., Sabina, J., Zuker, M., and Turner, D.H. 1999. Expanded sequence dependence of thermodynamic parameters improves prediction of RNA secondary structure. J. Mol. Biol. 288: 911-940.

McCutcheon, J.P. and Eddy, S.R. 2003. Computational identification of non-coding RNAs in Saccharomyces cerevisiae by comparative genomics. Nucleic Acids Res. 31: 4119-4128.

Meier, U.T. 2005. The many facets of H/ACA ribonucleoproteins. Chromosoma 114: 1-14.

Mengel-Jorgensen, J., Jensen, S.S., Rasmussen, A., Poehlsgaard, J., Iversen, J.J., and Kirpekar, F. 2006. Modifications in Thermus thermophilus $23 \mathrm{~S}$ ribosomal RNA are centered in regions of RNARNA contact. J. Biol. Chem. 281: 22108-22117.

Mochizuki, Y., He, J., Kulkarni, S., Bessler, M., and Mason, P.J. 2004. Mouse dyskerin mutations affect accumulation of telomerase RNA and small nucleolar RNA, telomerase activity, and ribosomal RNA processing. Proc. Natl. Acad. Sci. 101: 10756-10761.

Ofengand, J. 2002. Ribosomal RNA pseudouridines and pseudouridine synthases. FEBS Lett. 514: 17-25.

Ofengand, J. and Bakin, A. 1997. Mapping to nucleotide resolution of pseudouridine residues in large subunit ribosomal RNAs from representative eukaryotes, prokaryotes, archaebacteria, mitochondria and chloroplasts. J. Mol. Biol. 266: 246-268.

Ofengand, J. and Fournier, M.J. 1998. The pseudouridine residues of ribosomal RNA: Number, location, biosynthesis, and function. In Modification and editing of RNA: The alteration of RNA structure and function (eds. H. Grosjean and R. Benne), pp. 229-253. ASM Press, Washington, DC.

Ogle, J.M., Brodersen, D.E., Clemons Jr., W.M., Tarry, M.J., Carter, A.P., and Ramakrishnan, V. 2001. Recognition of cognate transfer RNA by the 30 S ribosomal subunit. Science 292: 897-902.

Olivas, W.M., Muhlrad, D., and Parker, R. 1997. Analysis of the yeast genome: Identification of new non-coding and small ORFcontaining RNAs. Nucleic Acids Res. 25: 4619-4625. 
Omer, A.D., Ziesche, S., Decatur, W.A., Fournier, M.J., and Dennis, P.P. 2003. RNA-modifying machines in archaea. Mol. Microbiol. 48: 617-629.

Ridanpaa, M., van Eenennaam, H., Pelin, K., Chadwick, R., Johnson, C., Yuan, B., vanVenrooij, W., Pruijn, G., Salmela, R., Rockas, S., et al. 2001. Mutations in the RNA component of RNase MRP cause a pleiotropic human disease, cartilage-hair hypoplasia. Cell 104: 195-203.

Rozenski, J., Crain, P.F., and McCloskey, J.A. 1999. The RNA Modification Database: 1999 update. Nucleic Acids Res. 27: 196-197.

Ruggero, D., Grisendi, S., Piazza, F., Rego, E., Mari, F., Rao, P.H., Cordon-Cardo, C., and Pandolfi, P.P. 2003. Dyskeratosis congenita and cancer in mice deficient in ribosomal RNA modification. Science 299: 259-262.

Samarsky, D.A. and Fournier, M.J. 1999. A comprehensive database for the small nucleolar RNAs from Saccharomyces cerevisiae. Nucleic Acids Res. 27: 161-164.

Schattner, P., Decatur, W.A., Davis, C.A., Ares Jr., M., Fournier, M.J., and Lowe, T.M. 2004. Genome-wide searching for pseudouridylation guide snoRNAs: Analysis of the Saccharomyces cerevisiae genome. Nucleic Acids Res. 32: 4281-4296.

Schuwirth, B.S., Borovinskaya, M.A., Hau, C.W., Zhang, W., VilaSanjurjo, A., Holton, J.M., and Cate, J.H. 2005. Structures of the bacterial ribosome at $3.5 \AA$ resolution. Science 310: 827-834.

Selmer, M., Dunham, C.M., Murphy 4th, F.V., Weixlbaumer, A., Petry, S., Kelley, A.C., Weir, J.R., and Ramakrishnan, V. 2006. Structure of the 70S ribosome complexed with mRNA and tRNA. Science 313: 1935-1942.
Spahn, C.M., Beckmann, R., Eswar, N., Penczek, P.A., Sali, A., Blobel, G., and Frank, J. 2001. Structure of the 80 S ribosome from Saccharomyces cerevisiae-tRNA-ribosome and subunitsubunit interactions. Cell 107: 373-386.

Spahn, C.M., Gomez-Lorenzo, M.G., Grassucci, R.A., Jorgensen, R., Andersen, G.R., Beckmann, R., Penczek, P.A., Ballesta, J.P., and Frank, J. 2004. Domain movements of elongation factor eEF2 and the eukaryotic $80 \mathrm{~S}$ ribosome facilitate tRNA translocation. $E M B O$ J. 23: $1008-1019$.

Torchet, C., Badis, G., Devaux, F., Costanzo, G., Werner, M., and Jacquier, A. 2005. The complete set of H/ACA snoRNAs that guide rRNA pseudouridylations in Saccharomyces cerevisiae. RNA 11: 928-938.

Yoon, A., Peng, G., Brandenburg, Y., Zollo, O., Xu, W., Rego, E., and Ruggero, D. 2006. Impaired control of IRES-mediated translation in X-linked dyskeratosis congenita. Science 312: 902-906.

Yu, Y.-T., Terns, R.M., and Terns, M.P. 2005. Mechanisms and functions of RNA-guided RNA modification. In Fine-tuning of RNA modifications by modification and editing (ed. H. Grosjean), pp. 223-262. Springer, New York.

Yusupov, M.M., Yusupova, G.Z., Baucom, A., Lieberman, K., Earnest, T.N., Cate, J.H., and Noller, H.F. 2001. Crystal structure of the ribosome at $5.5 \AA$ resolution. Science 292: 883-896.

Yusupova, G.Z., Yusupov, M.M., Cate, J.H., and Noller, H.F. 2001. The path of messenger RNA through the ribosome. Cell 106: 233-241.

Zuker, M. 2003. Mfold web server for nucleic acid folding and hybridization prediction. Nucleic Acids Res. 31: 3406-3415. 

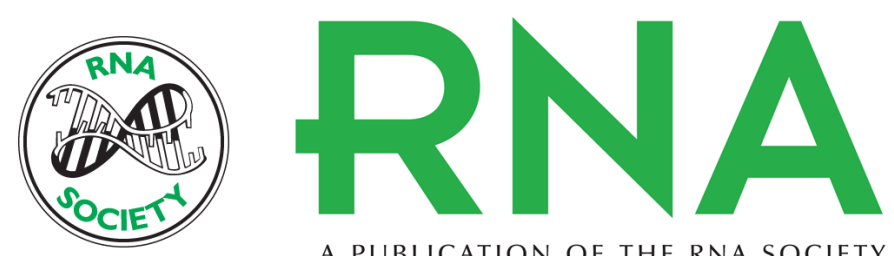

A PUBLICATION OF THE RNA SOCIETY

\section{New bioinformatic tools for analysis of nucleotide modifications in eukaryotic rRNA}

Dorota Piekna-Przybylska, Wayne A. Decatur and Maurille J. Fournier

RNA 2007 13: 305-312 originally published online February 5, 2007

Access the most recent version at doi:10.1261/rna.373107

\section{References This article cites 51 articles, 19 of which can be accessed free at: http://rnajournal.cshlp.org/content/13/3/305.full.html\#ref-list-1}

\section{License}
Email Alerting Receive free email alerts when new articles cite this article - sign up in the box at the Service top right corner of the article or click here.

To subscribe to RNA go to:

http://rnajournal.cshlp.org/subscriptions 